\title{
Exergy Analysis of a Subcritical Reheat Steam Power Plant with Regression Modeling and Optimization
}

\author{
MUHIB ALI RAJPER*, ABDUL GHAFOOR MEMON**, AND KHANJI HARIJAN** \\ RECEIVED ON 24.02.2016 ACCEPTED ON 11.05.2016
}

\begin{abstract}
In this paper, exergy analysis of a 210 MW SPP (Steam Power Plant) is performed. Firstly, the plant is modeled and validated, followed by a parametric study to show the effects of various operating parameters on the performance parameters. The net power output, energy efficiency, and exergy efficiency are taken as the performance parameters, while the condenser pressure, main steam pressure, bled steam pressures, main steam temperature, and reheat steam temperature isnominated as the operating parameters. Moreover, multiple polynomial regression models are developed to correlate each performance parameter with the operating parameters. The performance is then optimizedby using Direct-searchmethod. According to the results, the net power output, energy efficiency, and exergy efficiency are calculated as 186.5 MW, 31.37 and $30.41 \%$, respectively under normal operating conditions as a base case. The condenser is a major contributor towards the energy loss, followed by the boiler, whereas the highest irreversibilities occur in the boiler and turbine. According to the parametric study, variation in the operating parameters greatly influences the performance parameters. The regression models have appeared to be a good estimator of the performance parameters. The optimum net power output, energy efficiency and exergy efficiency are obtained as $227.6 \mathrm{MW}, 37.4$ and 36.4, respectively, which have been calculated along with optimal values of selected operating parameters.
\end{abstract}

Key Words: Energy Analysis, Exergy Analysis, Steam Power Plant, Regression Analysis, Optimization.

\section{INTRODUCTION}

The world's electricity needs are mainly met by fossil fuels. The development of renewable energy sources like solar and wind power has been growing remarkably; the reliance on fossil fuel is expected to continue for many years to come [1]. In Pakistan, more than $67 \%$ of electricity is generated by thermal power plants running on oil and gas in both public and private sectors [2]. Therefore, continuous efforts are underway to analyze them for efficient and cost-effective power production. The power plants are investigated by the first law of thermodynamics, however; during the recent decades, exergy analysis has gained considerable attention, which is based on the second law of thermodynamics. The exergy analysis leads to quantitative measurement of truelosses, known as exergy destruction or exergy losses with the identification of location. Therefore, many researchers have used exergy analysis as an investigative tool for different energy systems. For instance, Yang, et. al. [3] have investigated

\footnotetext{
* Jamshoro Power Company Limited, Jamshoro.

** Department of Mechanical Engineering, Mehran University of Engineering \&Technology, Jamshoro.
} 
a 660 MW ultra-supercritical and SPP and in China, according to which the exhaust flue gasses are the primary source of exergy destruction with $73.51 \%$ of the entire boiler subsystem. In many research articles with exergy as an analysis tool, like in [4-10], results have shown that the boiler incurs largest exergy destruction among other components. Exergy is also being used by many researchers for investigation of other types of the power plant. For instance, Carvalhoa, et. al. [11] have investigated an IC engine primed cogeneration plant, in which it is discussed that the combustion process in the engine cycle origins major exergy destruction.

Gogoi and Talukdar [12] have conducted a parametric study to investigate the effects of boiler pressure and fuel flow rate on the performance of a thermal power plant. According to the results, the fuel flow rate and boiler pressure have significant effects on the power cycle performance. Memon, et. al. [13] have performed thermodynamic analysis of an open cycle gas turbine power plant with MPR (Multiple Polynomial Regression) modeling and optimization.Parametric analysis is conducted to observe the Effects of various operating parameters on cycle performance and $\mathrm{CO}_{2}$ emission. In another article, Memon, et. al. [14] have performed the thermo-environmental, economic analyses with regression modeling and optimization of the simple and regenerative gas turbine cycles. Manesh, et. al. [15] have executed the exergoeconomic and exergoenvironmentalanalyses of a 315 MW SPP with a total site utility system. Rashid and Maihy[16] performed the energy and exergy analysis of Shobra El-Khima power plant in Cairo, Egypt. According to the results, around $28 \%$ of total exergy destruction occurs in the turbine, while the maximum energy loss occurs in the condenser which is around 55\% at different load conditions. Sengupata, et. al. [17] have conducted the exergy analysis of a coal based 210MW SPP with design parameters and focused on its exergetic performances under different loads.Srinivas, et. al. [18] have conducted thermodynamic analysis of a steam power plant to observe the effects of multiple number of feedwater heaters on its performance. According to their findings, efficiency improves with increase in the boiler pressure, turbine inlet temperature and furnace temperature with the optimum number of feed-water heaters.

In this paper, a comprehensive thermodynamic and statisticalanalysesare performed on a 210 MW SPP. Firstly, the power plant is modeled and simulated with the help of EES (Engineering Equation Solver), followed by the parametric study,which exhibits the effects of various operating parameters on the plant performance. The performance parameters considered are net power output, energy efficiency, and exergy efficiency, while condenser pressure, main steam pressure, bled steam pressures, main steam temperature and reheat steam temperature are nominated as the operating parameters.Afterward, MPR models are developedto determine a correlation of each performance parameter as a function of the operating parameters. Finally, optimization is performed to find optimal operating parameters corresponding to maximum plant performance.

\section{THERMODYNAMIC MODELING AND ASSUMPTIONS}

The schematic view of SPP under investigation is shown in Fig. 1. This figure exhibits a regenerative; reheat cycle unit with a capacityof 210 MWworking on the Rankine cycle. The feedwater regeneration process is carried out in four low-pressure heaters (H1, H2, H3 and H4), one deaerator (H5), three high-pressure heaters (H6, H7, and H8), one DC (Drain Cooler) and one Steam SC (Cooler).

The main steam from Superheater (SHT) is partially expanded in HPT (High Pressure Turbine) before routed to Reheater (RHT), followed by further expansions in IPT (Intermediate Pressure Turbine) and LPT (Low Pressure Turbine). The bled steam is extracted from various points of expansion processes for regeneration. The low-pressure steam leaves LPT for condensation in the condenser and then pumped to the boiler viathe intermediate stage of regeneration processes. 
Following are the thermodynamic model equations applied to the plant components and the SPP as a whole, to determine various thermodynamic quantities at each state point and performance parameters. Three fundamental balance equations are used for the development of these equations, namely, mass balance, energy balance and exergy balance. The use of such model equations for thermodynamic analysis of different systems is commonly practiced [1,3-18].

\section{$2.1 \quad$ Boiler}

The energy balance as applied to boiler yields

$\dot{\mathrm{Q}}_{\mathrm{B}}=\left[\dot{\mathrm{m}}_{17}\left(\mathrm{~h}_{20}-\mathrm{h}_{17}\right)+\dot{\mathrm{m}}_{27}\left(\mathrm{~h}_{17}-\mathrm{h}_{23}\right)\right]$

Moreover, the energy generated by the fuel is given as:

$\dot{\mathrm{Q}}_{\mathrm{F}}=\dot{\mathrm{m}}_{\mathrm{F}} \times(\mathrm{LHV})$

where LHV (Lower Heating Value) of the fuel, i.e. natural gas (modeled as pure methane) taken as $40.1 \mathrm{MJ} / \mathrm{kg}$ [4].

Then the boiler efficiency is defined as:

$\eta_{\mathrm{B}}=\frac{\dot{\mathrm{Q}}_{\mathrm{B}}}{\dot{\mathrm{Q}}_{\mathrm{F}}}$
When an exergy balance is applied to the boiler, irreversibilities occur in the boiler is given as:

$\dot{\mathrm{I}}_{\mathrm{B}}=\dot{\mathrm{E}} \mathrm{x}_{\mathrm{F}}+\left(\dot{\mathrm{E}} \mathrm{x}_{17}+\dot{\mathrm{E}} \mathrm{x}_{23}\right)-\left(\dot{\mathrm{E}} \mathrm{x}_{20}+\dot{\mathrm{E}} \mathrm{x}_{27}\right)$

Where $\dot{E} x_{F}$ is the rate of exergy supplied to the plant which is given as:

$e x_{F}=m_{F} \times e x_{F}$

Where $\mathrm{X}_{\mathrm{F}}$ is the fuel specific exergy approximated as [4]:

$$
e x_{F}=\left(1.033+\frac{0.0168 k}{j}-\frac{0.0698}{k}\right)(L H V)_{F}
$$

where $\mathrm{j}$ and $\mathrm{k}$ are constants taken as Equations (1 and 4), respectively for methane.

\subsection{Steam Turbines}

The overall power output from the turbines is given as:

$\dot{\mathrm{W}}_{\mathrm{T}}=\dot{\mathrm{W}}_{\mathrm{HPT}}+\dot{\mathrm{W}}_{\mathrm{IPT}}+\dot{\mathrm{W}}_{\mathrm{LPT}}$

where power outputs from each turbine can be determined by using the energy balance as given below:

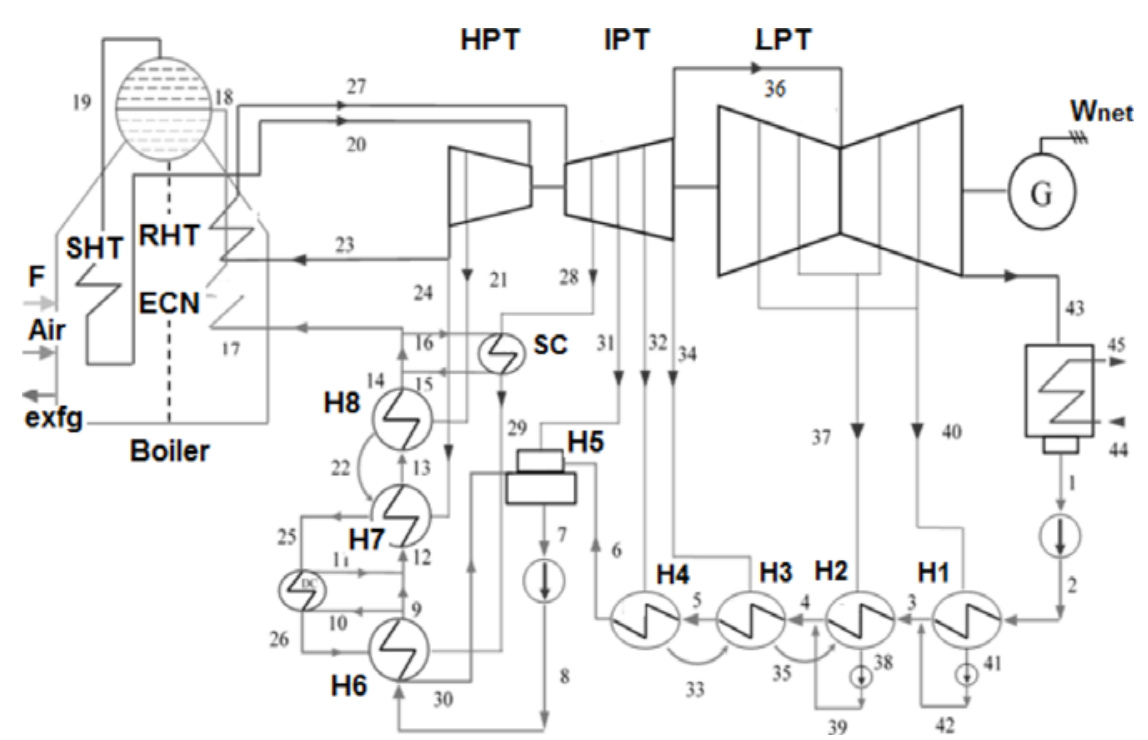

FIG. 1. SCHEMATIC VIEW OF 210 MW JAMSHORO STEAM POWER PLANT 
$\dot{\mathrm{W}}_{\mathrm{HPT}}=\eta_{\mathrm{T}}\left[\dot{\mathrm{m}}_{20}\left(\mathrm{~h}_{20}-\mathrm{h}_{21}\right)-\left(\dot{\mathrm{m}}_{20}-\dot{\mathrm{m}}_{21}\right)\left(\mathrm{h}_{21}-\mathrm{h}_{23}\right)\right]$

$\dot{\mathrm{W}}_{\text {IPT }}=\eta_{\mathrm{T}}\left[\begin{array}{l}\dot{\mathrm{m}}_{27}\left(\mathrm{~h}_{27}-\mathrm{h}_{28}\right)-\left(\dot{\mathrm{m}}_{27}-\dot{\mathrm{m}}_{28}\right)\left(\mathrm{h}_{28}-\mathrm{h}_{31}\right)+ \\ \left(\dot{\mathrm{m}}_{27}-\dot{\mathrm{m}}_{28}-\dot{\mathrm{m}}_{31}\right)\left(\mathrm{h}_{31}-\mathrm{h}_{32}\right)+ \\ \left(\dot{\mathrm{m}}_{27}-\dot{\mathrm{m}}_{28}-\dot{\mathrm{m}}_{31}-\dot{\mathrm{m}}_{32}\right)\left(\mathrm{h}_{32}-\mathrm{h}_{34}\right)\end{array}\right]$

and

$\dot{\mathrm{W}}_{\mathrm{LPT}}=\eta_{\mathrm{T}}\left[\begin{array}{l}\dot{\mathrm{m}}_{36}\left(\mathrm{~h}_{36}-\mathrm{h}_{37}\right)-\left(\dot{\mathrm{m}}_{36}-\dot{\mathrm{m}}_{37}\right)\left(\mathrm{h}_{37}-\mathrm{h}_{40}\right) \\ +\left(\dot{\mathrm{m}}_{36}-\dot{\mathrm{m}}_{37}-\dot{\mathrm{m}}_{40}\right)\left(\mathrm{h}_{40}-\mathrm{h}_{43}\right)\end{array}\right]$

where, $\eta_{\mathrm{T}}$ is the turbine mechanical efficiency taken as $90 \%$.

By applying the exergy balance, irreversibilitiesof the steam turbine can be determined as:

$\dot{\mathrm{I}}_{\mathrm{T}}=\left(\dot{\mathrm{Ex}}_{20}+\dot{\mathrm{Ex}}{ }_{27}\right)-\left(\begin{array}{l}\dot{\mathrm{Ex}_{21}}+\dot{\mathrm{E}} \mathrm{x}_{23}+\dot{\mathrm{Ex}} \mathrm{x}_{28}+\dot{\mathrm{E}} \mathrm{x}_{31}+ \\ \dot{\mathrm{E}} \mathrm{x}_{32}+\dot{\mathrm{Ex}}_{34}+\dot{\mathrm{E}} \mathrm{x}_{37}+\dot{\mathrm{Ex}}_{40}+\dot{\mathrm{Ex}}_{43}-\dot{\mathrm{W}}_{\mathrm{T}}\end{array}\right)$

\subsection{Condenser}

An energy balance as applied to the condenser gives:

$\dot{\mathrm{m}}_{43}\left(\mathrm{~h}_{43}+\mathrm{h}_{1}\right)=\dot{\mathrm{m}}_{44}\left(\mathrm{~h}_{45}-\mathrm{h}_{44}\right)$

An exergy balance for condenser leads to:

$\dot{\mathrm{I}}_{\mathrm{c}}=\left(\dot{\mathrm{E}} \mathrm{x}_{43}+\dot{\mathrm{E}} \mathrm{x}_{44}\right)-\left(\dot{\mathrm{Ex}} \mathrm{x}_{1}+\dot{\mathrm{E}} \mathrm{x}_{45}\right)$

\subsection{Pumps}

The condensate pump and the feedwater pump consume power given respectively as:

$$
\begin{aligned}
& \dot{\mathrm{W}}_{\mathrm{cp}}=\dot{\mathrm{m}}_{1}\left(\mathrm{~h}_{2}-\mathrm{h}_{1}\right) \\
& \dot{\mathrm{W}}_{\mathrm{fwp}}=\dot{\mathrm{m}}_{7}\left(\mathrm{~h}_{8}-\mathrm{h}_{7}\right)
\end{aligned}
$$

The amount of irreversibilities encountered in the pumps is given as:
$\dot{\mathrm{I}}_{\mathrm{cp}}=\dot{\mathrm{E}} \mathrm{x}_{2}+\dot{\mathrm{E}} \mathrm{x}_{1}-\dot{\mathrm{W}}_{\mathrm{cp}}$

and

$$
\dot{\mathrm{I}}_{\mathrm{fwp}}=\dot{\mathrm{E}} \mathrm{x}_{8}+\dot{\mathrm{E}} \mathrm{x}_{7}-\dot{\mathrm{W}}_{\mathrm{fwp}}
$$

\subsection{Heaters and Deaerator}

An energy balance applied to combined HPHs and LPHs yields respectively as:

$\dot{\mathrm{m}}_{21} \mathrm{~h}_{21}+\dot{\mathrm{m}}_{24} \mathrm{~h}_{24}+\dot{\mathrm{m}}_{28} \mathrm{~h}_{28}-\dot{\mathrm{m}}_{30} \mathrm{~h}_{30}=\dot{\mathrm{m}}_{17} \mathrm{~h}_{17}-\dot{\mathrm{m}}_{8} \mathrm{~h}_{8}$

$\dot{\mathrm{m}}_{32} \mathrm{~h}_{32}+\dot{\mathrm{m}}_{34} \mathrm{~h}_{34}+\dot{\mathrm{m}}_{37} \mathrm{~h}_{37}-\dot{\mathrm{m}}_{40} \mathrm{~h}_{40}=\dot{\mathrm{m}}_{6} \mathrm{~h}_{6}-\dot{\mathrm{m}}_{2} \mathrm{~h}_{2}$

Similarly, for the deaerator, energy balance yields:

$$
\dot{\mathrm{m}}_{31} \mathrm{~h}_{31}+\dot{\mathrm{m}}_{30} \mathrm{~h}_{30}+\dot{\mathrm{m}}_{6} \mathrm{~h}_{6}=\dot{\mathrm{m}}_{7} \mathrm{~h}_{7}
$$

For obtaining the irreversibilities in these components, exergy balances applied to these components as follows:

$$
\begin{aligned}
& \dot{\mathrm{I}}_{\mathrm{HPH}}=\dot{\mathrm{E}} \mathrm{x}_{21}+\dot{\mathrm{E}} \mathrm{x}_{24}+\dot{\mathrm{E}} \mathrm{x}_{28}+\dot{\mathrm{E}} \mathrm{x}_{8}+\dot{\mathrm{E}} \mathrm{x}_{17}-\dot{\mathrm{E}} \mathrm{x}_{30} \\
& \dot{\mathrm{I}}_{\mathrm{LPH}}=\dot{\mathrm{E}} \mathrm{x}_{2}+\dot{\mathrm{E}} \mathrm{x}_{32}+\dot{\mathrm{E}} \mathrm{x}_{34}+\dot{\mathrm{E}} \mathrm{x}_{37}+\dot{\mathrm{E}} \mathrm{x}_{40}-\dot{\mathrm{E}} \mathrm{x}_{6}
\end{aligned}
$$

Moreover, relation for irreversibilities in the deaerator is given as:

$$
\dot{\mathrm{I}}_{\mathrm{H} 5}=\dot{\mathrm{E}} \mathrm{x}_{6}+\dot{\mathrm{E}} \mathrm{x}_{33}+\dot{\mathrm{E}} \mathrm{x}_{31}-\dot{\mathrm{E}} \mathrm{x}_{7}
$$

\subsection{Overall Plant}

The net power output is determined from:

$\dot{\mathrm{W}}_{\mathrm{NET}}=\dot{\mathrm{W}}_{\mathrm{T}}-\dot{\mathrm{W}}_{\mathrm{cp}}-\dot{\mathrm{W}}_{\mathrm{fwp}}$

The energy efficiency is given as:

$$
\eta_{\text {thermal }}=\frac{\dot{W}_{N E T}}{\dot{Q}_{F}}
$$


The exergy efficiency is given as:

$$
\varepsilon=\frac{\dot{\mathrm{W}}_{\mathrm{NET}}}{\dot{\mathrm{E}} \mathrm{x}_{\mathrm{F}}}
$$

The application of these model equations is subject to the following assumptions:

(i) Steady-state operation of all system components.

(ii) Change in the kinetic energy (and exergy) and potential energy (and exergy) of the fluid streams are neglected.

(iii) Fuel is natural gas modeled as methane $\left(\mathrm{CH}_{4}\right)$ only.

(iv) The dead-state condition is at $101.325 \mathrm{kPa}$ and 298 K.

(v) Cooling water temperature difference is $10 \mathrm{~K}$.

(vi) The pressure drop in FWHs and boiler heat exchangers is $0.5-1.0 \%$

\section{MULTIPLE POLYNOMIAL REGRESSIONAND OPTIMIZATION}

The MPR models are developed to describe the relationship between each of the response variable (performance parameter) with the predictor variables (operating parameters). In this regard, a best-fit regression equation is calculated by using the method of least squares, such that the distances between the simulated values and the predicted values estimated by the model equation are minimized. The coefficient of determination $\left(\mathrm{R}^{2}\right.$-value) is calculated to check the accuracy of estimation, which is defined as:

$$
\mathrm{R}^{2}=1-\frac{\sum(\mathrm{y}-\hat{\mathrm{y}})^{2}}{\sum(\mathrm{y}-\overline{\mathrm{y}})^{2}}
$$

where $y$ is the simulated value, $\hat{y}$ is the value from the approximation, $\bar{y}$ is mean of the simulated values. The net power output, energy efficiency and exergy efficiency are considered as response variables, while the condenser pressure, main steam pressure, bled steam pressures $\mathrm{P}_{21}$, $\mathrm{P}_{24}$ and $\mathrm{P}_{28}$ are the predictor variables. The regression models are valid to estimate the response variable from the predictor variables in the range given in Table 1 . In this study, optimization is performed by considering each response variable as objective functions, which are to be maximized by varying the multiple predictor variables. Such a multi-dimensional optimization is processed by using direct-search method. A direct-search algorithm works on finding a set of points around the "current" point, looking for one where the value of the objective function is lower than the value at the current point. In this way an optimal value of the objective function is arrived depending on the number of maximum function calls and relative convergence tolerance fixed in the software.

TABLE 1. VALUES OF OPERATING PARAMETERS FOR PARAMETRIC STUDY[18-19]

\begin{tabular}{|c|c|c|}
\hline Operating Parameters & Values for Base Case & Range of Values for Parametric Study \\
\hline Condenser pressure (P1) & $11.23(\mathrm{kPa})$ & $1-0$ \\
\hline Main steam pressure (P20) & $13200(\mathrm{kPa})$ & $12750-13700$ \\
\hline Bled steam extraction 1 pressure (P21) & $3828(\mathrm{kPa})$ & $2640-5148$ \\
\hline Bled steam extraction 2 pressure (P23) & $2388.67(\mathrm{kPa})$ & $680-1543$ \\
\hline Bled steam extraction 3 pressure (P28) & $1139.16(\mathrm{kPa})$ & $711-901$ \\
\hline Main steam temperature (T20) & $811.1(\mathrm{~K})$ & $711-901$ \\
\hline Reheat steam temperature(T27) & $811.1(\mathrm{~K})$ & \\
\hline
\end{tabular}

Mehran University Research Journal of Engineering \& Technology, Volume 35, No. 3, July, 2016 [p-ISSN: 0254-7821, e-ISSN: 2413-7219] 


\section{MODEL VALIDATION}

Various thermodynamic quantities at all salient points have been calculated by simulationunder normal operating conditions (as a base case) of the plant. The values of different operating parameters in the base case operation are listed in Table 1 along with the ranges of values for parametric study.

The model is validated by comparing the simulated enthalpy values at various bled steam extraction points with the designed values assigned to same locations in the plant data script named "thermodynamic performance" [19]. The access to the designed data was provided by the power plant authorities, which were acquainted during the commissioning of the power plant. The simulated values of enthalpy are obtained by maintaining the same designed operating parameters (like pressure and temperature) in the program as given in the data script. This comparison is shown in Fig. 2, according to which there is an average difference of $0.28 \%$ between the designed and model values with the maximum one for $\mathrm{h}_{21}$, i.e. $1.02 \%$. It verifies the decent performance of the developed model.

\section{RESULTS AND DISCUSSION}

As a base case, the net power output, energy efficiency and exergy efficiency of the plant have been calculated as $186.5 \mathrm{MW}, 31.37$ and $30.41 \%$, respectively. Moreover, relative energy loss ratio and relative irreversibility ratio for various plant components have been obtained and exhibited in Fig. 3. According to Fig. 3, condenser is liable to largest energy loss among all componentssince huge amount of heat is taken away by cooling water during the condensation process. As this heat transfer occurs at verylow-temperature difference, exergy analysis reflects a very low irreversibility in the condenser. On the other hand, heat transfer in the boiler occurs at veryhightemperature difference, and, therefore, it contributes a major share in the irreversibilities. Such an important outcome is reflected by only considering the exergy as an analysis tool. The second largest irreversibility among the components occurs in asteamturbine while other components share a little towards the losses. The contributions of irreversibilities in boiler and steam turbine are 82 and $11 \%$, respectively, which are in agreement with the findings in similar works by Yang, et. al. [3], Aljundi [4] and Srinivas, et. al. [18]. This information can be used to increase the performance of the plant components by trying to minimize the energy losses and irreversibilities in a prioritized manner.

\subsection{Results of Parametric Study}

The parametric study has been conductedto evaluate the effects of various operating parameters on the

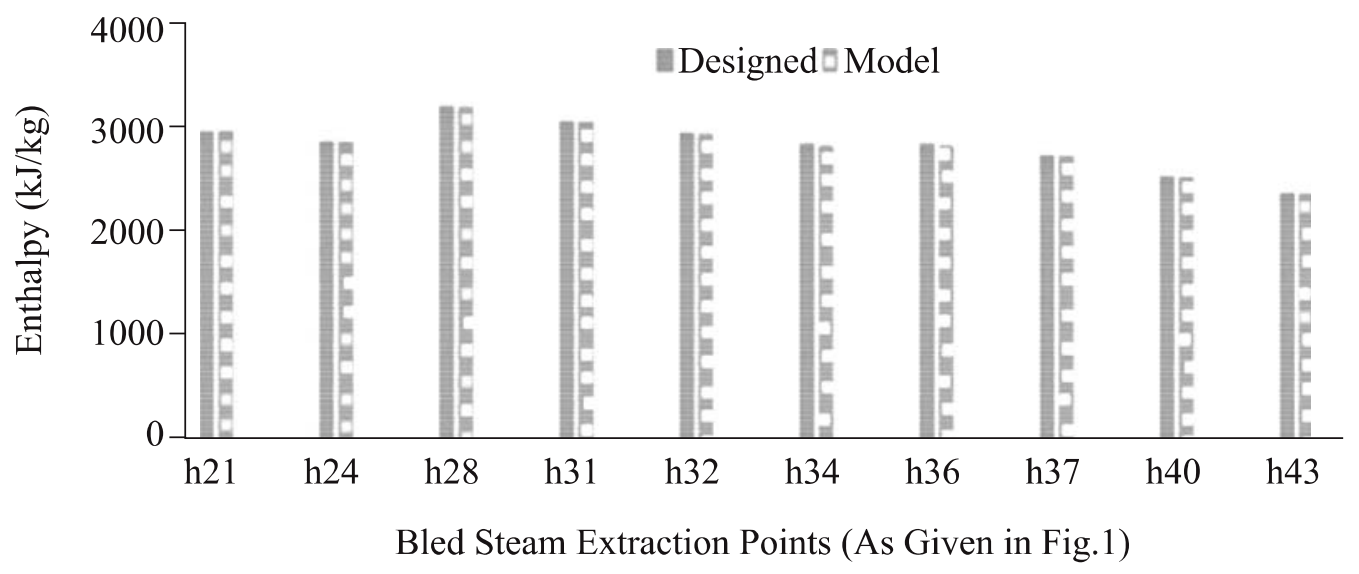

FIG. 2. COMPARISON BETWEEN DESIGNED AND MODELED ENTHALPY VALUES OF BLED STEAM EXTRACTIONS

Mehran University Research Journal of Engineering \& Technology, Volume 35, No. 3, July, 2016 [p-ISSN: 0254-7821, e-ISSN: 2413-7219] 
performance parameters. The range of variation in these operating parameters for conducting the parametric study is given in Table 2. Here, the net power output, energy efficiency, and exergy efficiency are taken as the performance parameters. The condenser pressure $\left(\mathrm{P}_{1}\right)$, main steam pressure $\left(\mathrm{P}_{20}\right)$, bled steam pressures $\left(\mathrm{P}_{21}, \mathrm{P}_{24}\right.$, $\left.\mathrm{P}_{28}\right)$, main steam temperature $\left(\mathrm{T}_{20}\right)$ and reheat steam temperature $\left(\mathrm{T}_{27}\right)$ are nominated as the operating parameters.

\subsubsection{Effect of Condenser Pressure on Performance}

Fig. 4 demonstrates the effect of condenser pressure on the performance parameters. According to Fig. 4, the net power output and efficiencies decrease with an increase in the condenser pressure, as demonstrated in the similar work of Yang, et. al. [3]. The diminutions are rather significant at lower values of condenser pressure. As the condenser pressure increases, the power output from LPT decreases, which causes a reduction in the net power output; and since the fuel consumption remains unchanged, the efficiencies also tend to decrease. In actual practice, the intended decrease in the condenser pressure is restricted due to the dropping of steam quality at the exit of LPT and possibility of air trap in the condenser. The diminution in steam quality at the exit of LPT causes a drop in the power output due to a thrust developed by the water droplets. Also, the low-quality steam, at very low condenser pressure causes corrosion in the rotary and stationary blades of LPT.

\subsubsection{Effect of Main Steam Pressure on Performance}

Fig. 5 illustrates the effect of main steam pressure on the cycle performance. From Fig. 5, it is evident that the net power output and efficiencies increase slightly with a rise in the main steam pressure. The amount of heat required to generate the steam at higher pressure decreases due to decrease in its latent heat of vaporization. Moreover, with an increase in the main steam pressure, the bled steam pressures also increase and with their fixed temperatures, their enthalpies decrease. This decreases feedwater temperature at the exit of each heater which consequently increases the heat required to generate the steam in the boiler. The overall effect is a marginal decline in the heat transfer to the boiler and hence a very slight increase in the efficiencies. The results are in great agreement with the same exhibited in the work of Yang, et. al. [3] and Srinivas, et. al. [18].

\subsubsection{Effect of Bled Steam Pressures on Performance}

The regeneration process is performed using bled steam extracted from three most important locations, i.e., intermediate stage of HPT expansion (state 21), the exit of HPT (state 24) and intermediate stage of IPT expansion (state 28). The selection of these locations is based on the pressure values, as the combined condensate from the HP-heaterscan be raised to feedwater tank without additional pumping. In Figs. 6-8 effects of varying bled steam pressures on the performance are demonstrated.

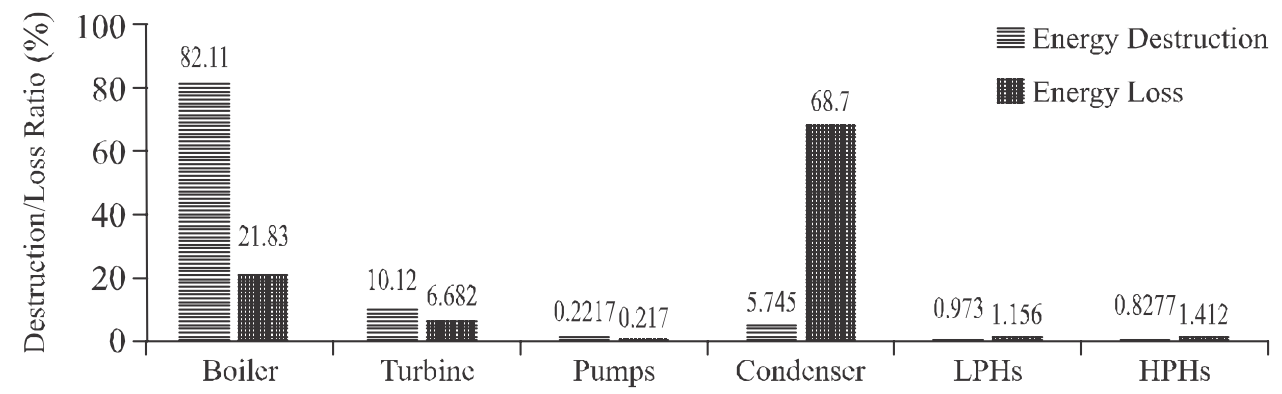

FIG. 3. RELATIVE ENERGY LOSS AND EXERGY DESTRUCTION RATIOS FOR DIFFERENT PLANT COMPONENTS

Mehran University Research Journal of Engineering \& Technology, Volume 35, No. 3, July, 2016 [p-ISSN: 0254-7821, e-ISSN: 2413-7219] 
According to Figs. 6-8, the net power output and efficiencies decrease with an increase in the pressure of bled steam from the turbines, and the trend of variation in each case is nearly similar. The primary reason for a reduction in the net power output is the decrease in the power outputs from HPT and IPT due to an earliersteam extraction from these turbines. The bled-steam with higher pressure also carries large enthalpy, which with same mass flow rate can surrender more heat in the feedwater heaters, thereby raises the temperature of feedwater. Because of high temperature, feedwater requires a lesser amount of heat to raise steam at the boiler pressure. Therefore,

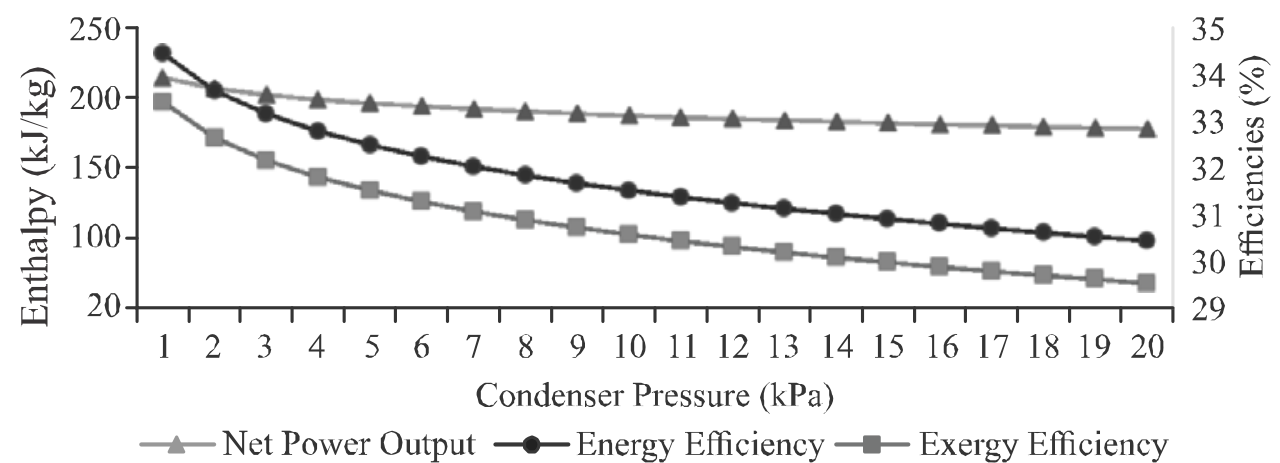

FIG. 4. EFFECT OF CONDENSER PRESSURE ON PERFORMANCE

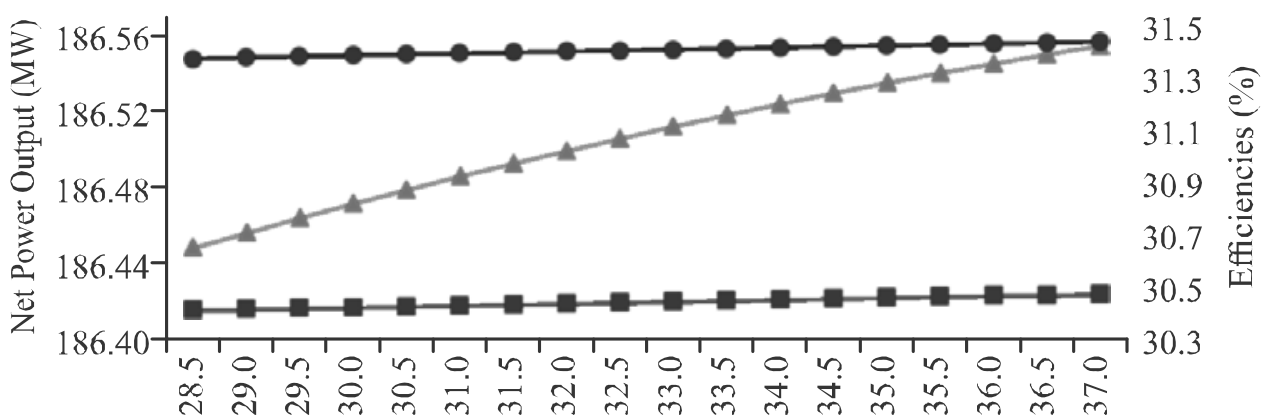

Main Steam Pressure $(\mathrm{kPa})$

$\multimap$ Net Power Output $\multimap$ Energy Efficiency $\longrightarrow$ Exergy Efficiency

FIG. 5. EFFECT OF STEAM PRESSURE ON PERFORMANCE

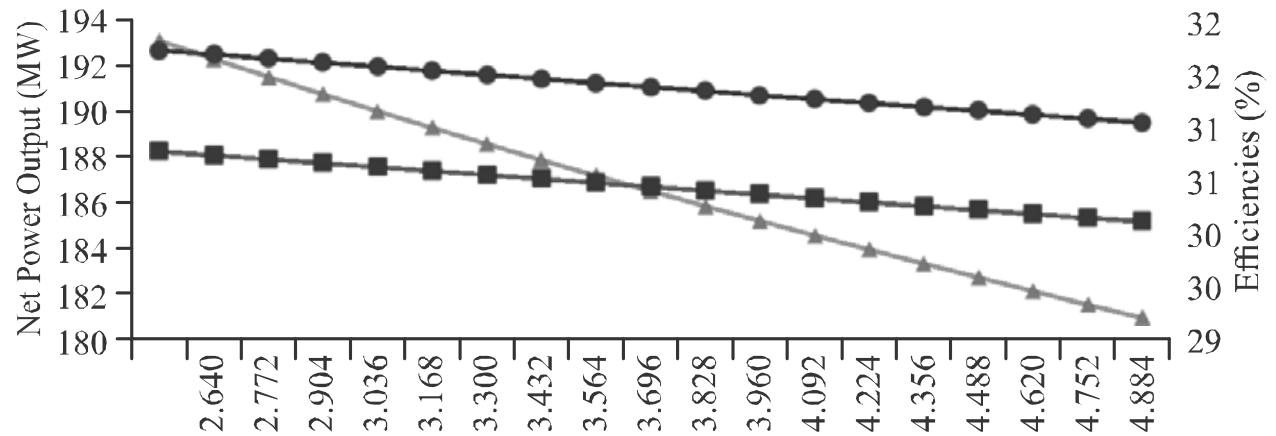

Bled Steam Pressure $(\mathrm{kPa})$

$\longrightarrow$ Net Power Output $\longrightarrow$ Thermal Efficiency —— Exergy Efficiency

FIG. 6. EFFECT OF BLED STEAM PRESSURE (P21) ON PERFORMANCE 
required amount of fuel per unit mass of steam generation in the boiler decreases. However, the diminution in the net power output is more significant than the decrease in the fuel supply to the boiler, hence causes the efficiencies to decrease. From an exergy point of view, exergy efficiency decreases with the bled steam pressures mainly because work output decreases, which is more valuable commodity (on the basis of quality).

It is evident from the above discussion the rise in bled steam pressures is not justifiable with the given number of feedwater heaters. The impact of bled steam pressures may be analyzed in connection with an additional parameter, the optimum number of feedwater heaters, for furthering the current analysis. Not much information is reported in the literature to investigate the impact of bled steam pressures on performance of steam power cycles. In work by Srinivas, et. al. [18], however, the impact of bled steam temperature ratio (which varies corresponding to pressure) on performance is investigated for a single feedwater heater. As a comparison, there is a profound consensus in the results for efficiencies.

\subsubsection{Effect of Main Steam Temperature on Performance}

Fig. 9 displays the effect of main steam temperature on the performance. According to Fig. 9, the performance parameters increase with a rise in the main steam temperature. The trend of variation in the efficiency is in agreement with Yang, et. al. [3] and Srinivas, et. al. [18]. Due to increase in the main steam temperature, the enthalpy of steam at the inlet of HPT increases, this

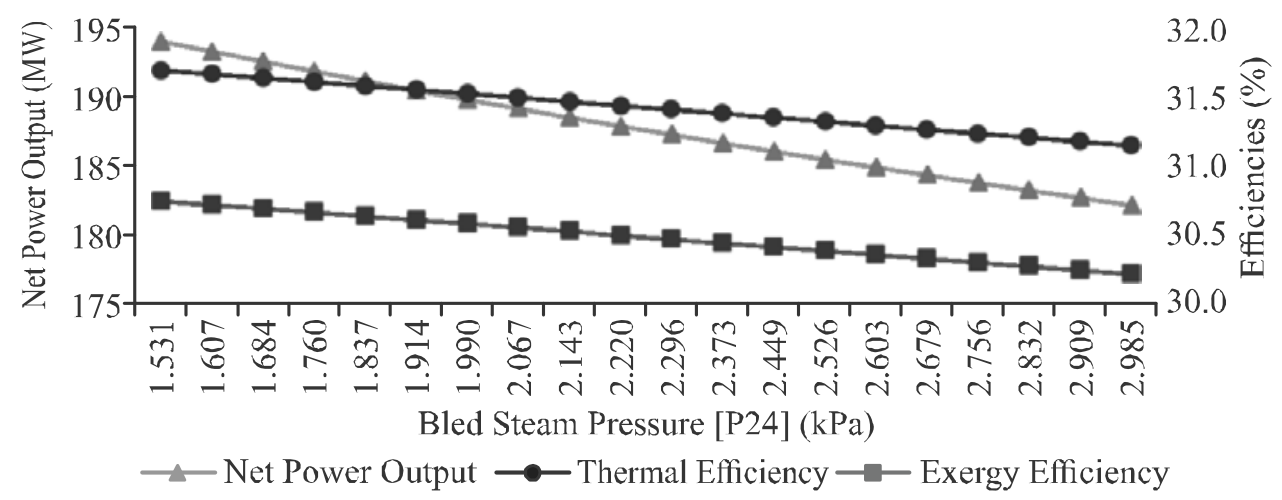

FIG. 7. EFFECT OF BLED STEAM PRESSURE (P24) ON PERFORMANCE

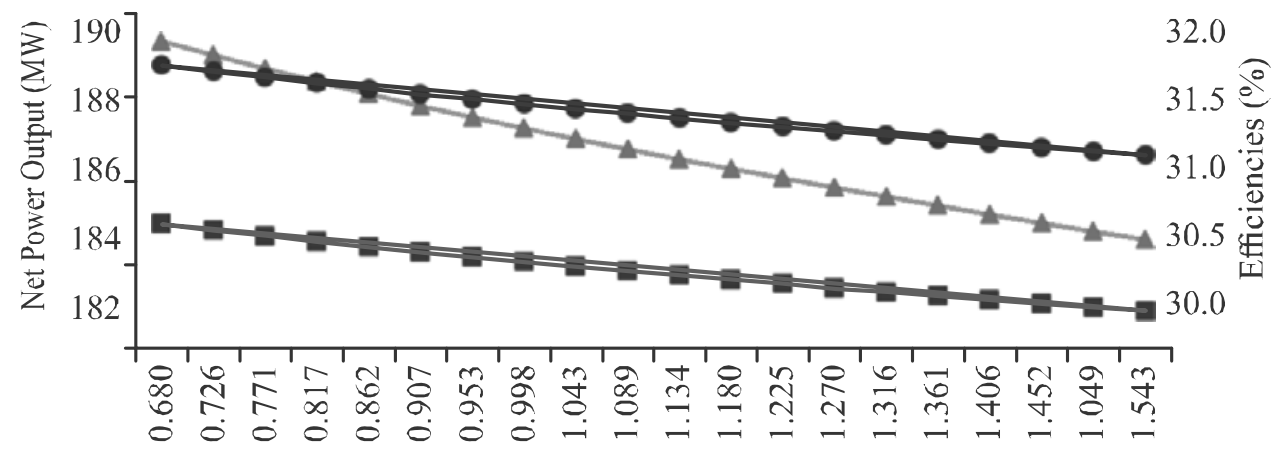

Bled Steam Pressure [P28] $(\mathrm{kPa})$

$\longrightarrow$ Net Power Output $\longrightarrow$ Thermal Efficiency $\longrightarrow$ Exergy Efficiency

FIG. 8. EFFECT OF BLED STEAM PRESSURE (P28) ON PERFORMANCE 
causes an increase in the net power output. Consequently, to generate high-temperature steam, the rate of heat transfer required in the boiler also increases, but as the incremental rise in net power output is more significant, efficiencies tend to rise. The figure displays a steadyincrease in the performance parameters onincreasing in the main steam temperature. However, such an enhancement in the performance always accompanied by a proportional rise in the capital cost, which stems due to improvement needed in the turbine blade and boiler tube design/material. The incremental revenues generated by the improved power output with higher efficiencies may be favorable only if the economic parameters also indicate so.

\subsubsection{Effect of Reheat Steam Temperature on Performance}

Fig. 10 exhibits the effect of reheat steam temperature on the performance. Fig. 10 shows uniform increase in the performance with an increase in the reheat steam temperature. Again, a great consensus is developed with the results obtained by Yang, et. al. [3]. In requiring a reheated steam at a higher temperature, more heat is needed in the boiler, but that also causes a proportional increase in the power output from IPT; however, the latter is more significant. Additionally, the feedwater temperature increases due to the availability of bled steam at higher temperatures for regeneration.

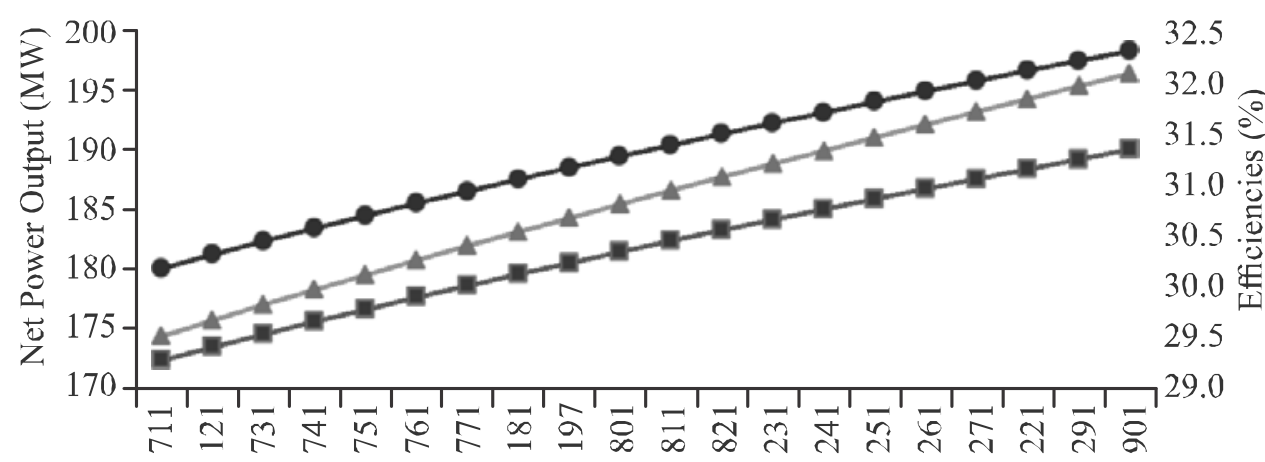

Main Steam Temprature (K)

$\longrightarrow$ Net Power Output $\longrightarrow$ - Thermal Efficiency —- Exergy Efficiency

FIG. 9. EFFECT OF MAIN STEAM TEMPERATURE ON PERFORMANCE

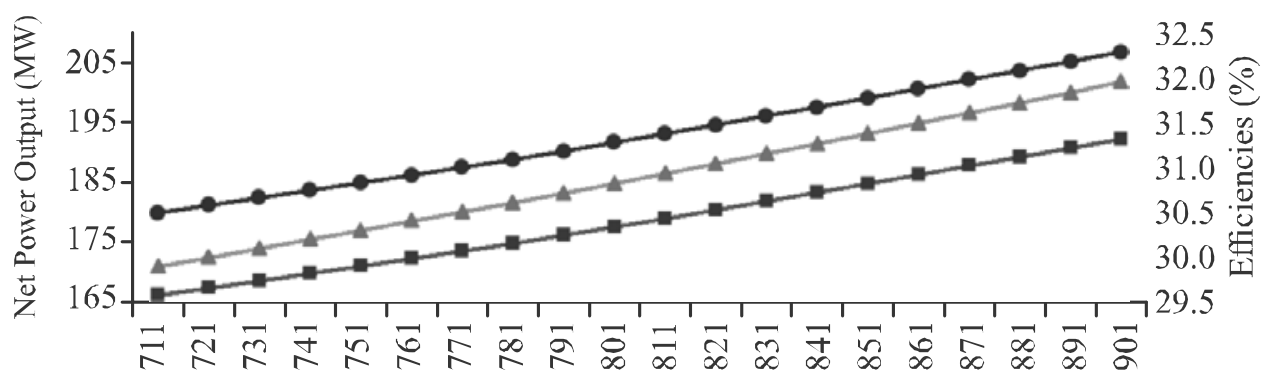

Reheat Steam Temprature (K)

$\longrightarrow$ Net Power Output $\longrightarrow$ Thermal Efficiency $\longrightarrow$ Exergy Efficiency

FIG. 10. EFFECT OF REHEAT STEAM TEMPERATURE ON PERFORMANCE 


\subsection{Results of MPR Modeling and Optimization}

The MPR models with corresponding $\mathrm{R}^{2}$ values and optimal operating conditions are given in Table 2 . Table 2 that the MPR models are appended with a reasonable coefficient of determination, which indicates that the predictor variables are a good estimator of the response variable. Such models can be used to estimate the

TABLE 2. MULTIPLE REGRESSION MODELS AND OPTIMUM OPERATING CONDITIONS

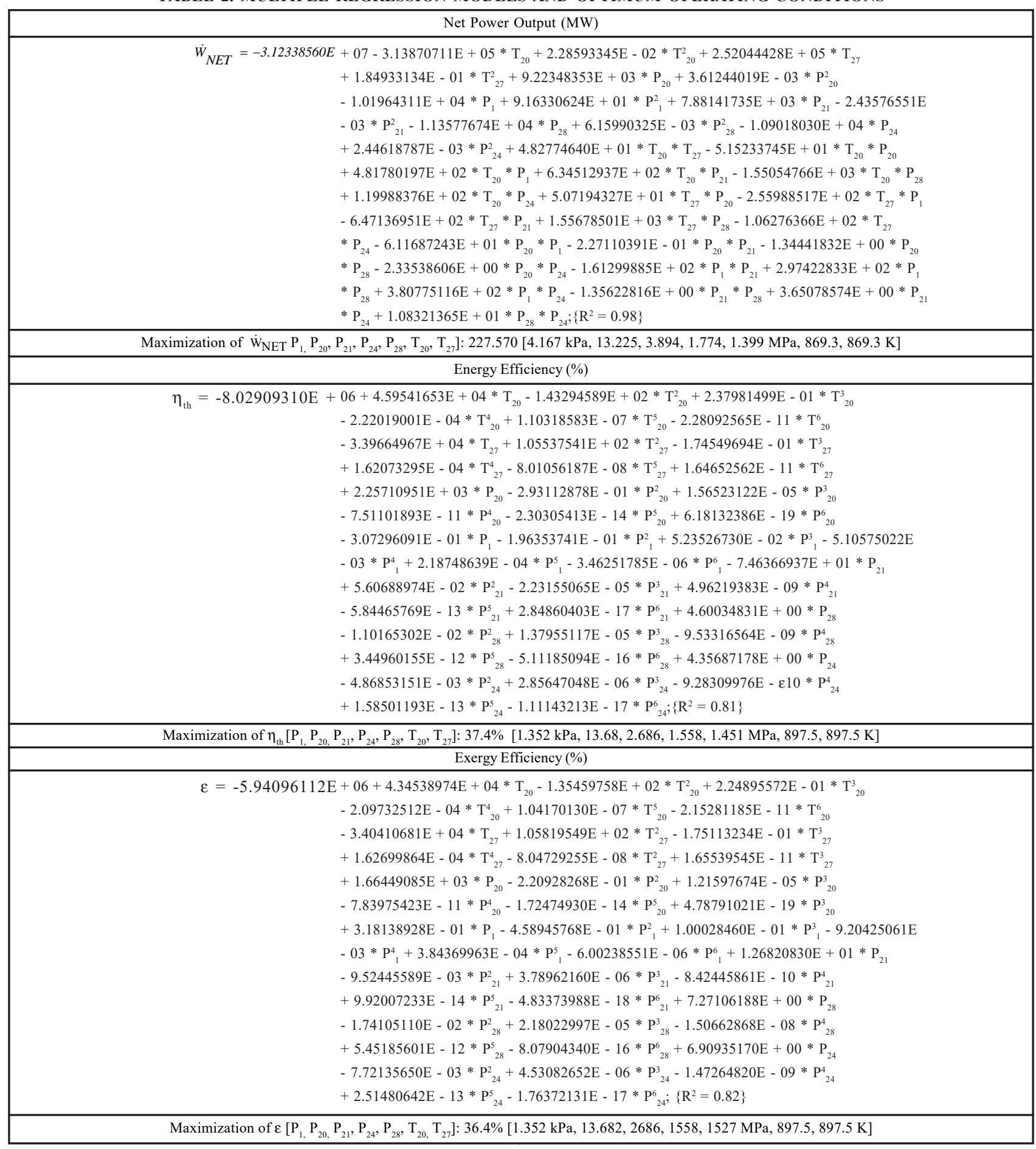


performance parameters readily with the given (onsite) operating parameters of the SPP under consideration. Moreover, the optimum net power output of 227.6 MW is achieved with given optimal operating parameters. Different optimal values of these operating parameters are obtained for the optimum efficiencies. The power plant operation under these optimal operating parameters may lead to a higher power output and efficiencies with lower environmental effect. The optimal energy efficiency is higher than the optimal exergy efficiency under similar optimal operating parameters. This is because fuel exergy is higher than the fuel energy. It is also evident that the optimal pressure values are rather higher for obtaining maximum power as compare to maximum efficiencies.

\section{CONCLUSION}

In this study, a comprehensive exergetic and regression modeling of a regenerative, reheat SPP was conducted. The plant performance such as net power output, energy efficiency, and exergy efficiency were calculated as $186.5 \mathrm{MW}, 31.37 \%$ and $30.41 \%$, respectively under normal operating conditions as a base case. The results of exergy analysis have shown that the boiler contributes a major share towards irreversibilities, mainly due to heat transfer at large temperature difference, which is followed by a steam turbine, while other components contribute a little towards irreversibilities. From the parametric study conducted, it has been observed that the operating parameters greatly influence the performance parameters of the plant. The performance parameters increase with main steam pressure, main steam temperature and reheat temperature, while decrease in condenser pressure and bled steam pressures. The MPR model equations were developed to correlate each of the response variables with the predictor variables and found estimating each response variable with a great degree of accuracy, as appended with reasonable $\mathrm{R}^{2}$ values. The optimum net power output and efficiencies were obtained as 227.6
MW and $37.4 \%$, respectively. These values are corresponding to the optimal operating parameters with higher possible main steam pressure and temperature and lower possible condenser pressure. However, these conditions are constrained by additional costs and metallurgical limits.

\section{NOMENCLATURE}

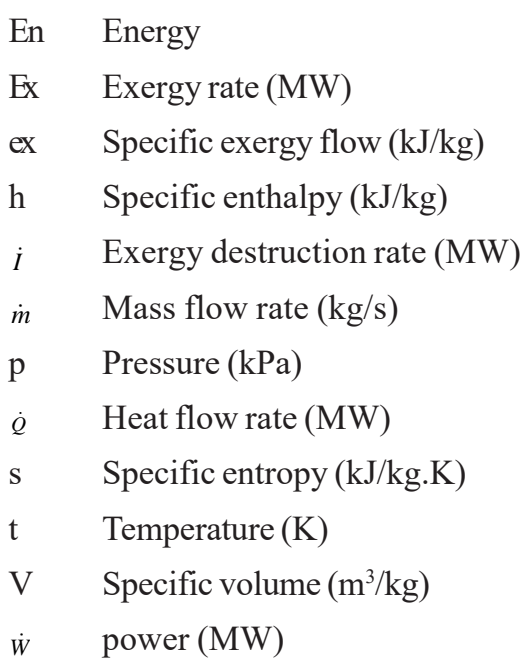

\section{Greek Letters}

$\psi \quad$ Specific exergy rate (MW)

$\varepsilon \quad$ Exergy efficiency

$\eta \quad$ Energy efficiency

\section{Abbreviations}

Ext Extraction

HPT High pressure turbine

IPT Intermediate pressure turbine

LHV Lower heating value LPT Low pressure turbine

SPP Steam power plant

T Turbine

\section{Subscripts}

B Boiler

bfp Boiler feed pump

C Condenser

cp Condensate pump

cons Consumption

DC Drain cooler

exfg Exhaust flue gases 


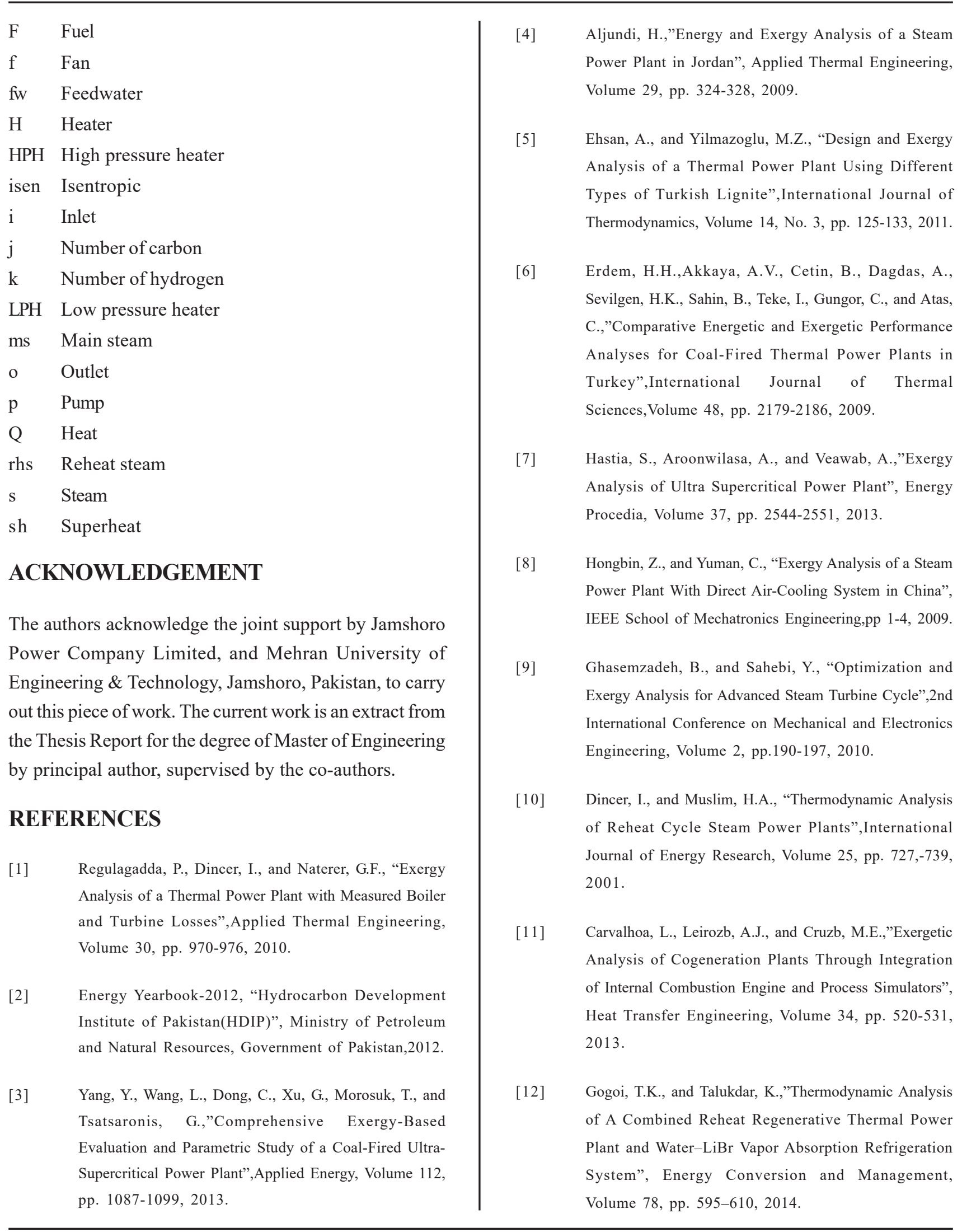


[13] Memon, A.G., Memon, R.A., Harijan, K., and Uqaili, M.A.,"Thermo-Environmental Analysis of an Open Cycle Gas Turbine Power Plant with Regression Modeling and Optimization", Journal of the Energy Institute, Volume87, pp. 1-8, 2014.

[14] Memon, A.G., Harijan, K., Uqaili, M.A., and Memon, R.A.,"Thermo-Environmental and Economic Analysis of Simple and Regenerative Gas Turbine Cycles With Regression Modeling and Optimization",Energy Conversion and Management, Volume 76, pp. 852-864, 2013.

[15] Manesh, K., Navid, P., Baghestani, M., Abadi, S., Rosen, M.A., Blanco, AM., and Amidpour, M., "Exergoeconomic and Exergoenvironmental Evaluation of the Coupling of a Gas Fired Steam Power Plant with a Total Site Utility System”, Energy Conversion and Management, Volume 77, pp. 469-483, 2013.
[16] Rashad, and Maihy, A.E., "Energy and Exergy Analysis of a Steam Power Plant in Egypt",13th International Conference on Aerospace Sciences \& Aviation Technology, pp. 1-12, 2009.

[17] Sengupta, S., Datta, A., and Duttagupta, S., "Exergy Analysis of a Coal-Based 210 MWThermal Power Plant”, International Journal of Energy Research, Volume 31, No. 1, pp.14-28, 2007.

[18] Srinivas, T., Gupta, A.V.S.S.K.S., and Reddy, B.V.,"Generalized Thermodynamic Analysis of Steam Power Cycles with ' $n$ ' Number of Feedwater Heaters",International Journal of Thermodynamics, Volume 10, No. 4, pp. 177-185, 2007.

[19] Report on Thermodynamic Performance, China Machinery Engineering Corporation (CMEC) China, 1988 (http://www.cmec.com/html/index.php). Access provided by Jamshoro Power Company, Pakistan. 